\title{
A TRANSIÇÃO DA EDUCAÇÃO INFANTIL PARA O ENSINO FUNDAMENTAL: UMA TEORIA PARA ORIENTAR O PENSAR E O AGIR DOCENTES
}

Suely Amaral Mello

Resumo: Com este artigo, quero problematizar a necessidade de uma formação teórica sólida dos professores e professoras também da educação infantil e do ensino fundamental numa perspectiva de educação que promova o desenvolvimento humano. Dada a nova compreensão do papel da educação na constituição do humano em cada um de nós, a intencionalidade docente se faz essencial para enfrentar o desafio colocado por Gramsci (1979) à escola e ao professor ou professora: formar cada criança para ser um dirigente. Para isso, trago algumas contribuições da teoria histórico-cultural para compreender o desenvolvimento humano e busco as implicações desta concepção, o que reforça a importância da apropriação/construção substancial de uma teoria pedagógica por parte dos docentes que possa orientar seu pensar e concretizar-se sob a forma de práticas pedagógicas desenvolventes.

Palavras chave: Integração Educação Infantil e Ensino Fundamental. Articulação teoria e prática. Teoria histórico-cultural.

${ }^{1}$ Professora do Programa de Pós Graduação em Educação da Faculdade de Filosofia e Ciências UNES UNESP/Marília. SP. 


\section{FROM EARLY CHILDHOOD EDUCATION TO ELEMENTARY SCHOOL: A THEORYTO SUPORT TEACHER'S THINKING AND ACTING}

Abstract: The purpose of this article is to discuss the need of a solid theoretical education for elementary school and early childhood teachers in a developmental perspective. Given the new understanding of the education role in the constitution of human qualities in each of us, teacher's intentionality becomes essential to face the challenge posed by Gramsci (1979) to school and to teacher: to bring up each child to be a leader. For this debate, we bring some contributions from the historical-cultural theory to understand human development and seek the implications of this approach to education. This reinforces the importance of a substantial appropriation/construction of a pedagogical theory by the teachers, which can guide their thinking and practices for developmental education.

Keyw ords: Integration between Early Childhood Education and Elementary School. Theory and practice. Historical-cultural theory.

\section{DESDE LA EDUCACIÓN INFANTIL A LA ESCUELA ELEMENTAR: UNA TEORÍA PARA ORIENTAR EL PENSAR Y LA ACCIÓN DOCENTE}

Resumen: Con este artículo, quiero problematizar la necesidad de una formación teórica sólida de los maestros y maestras también de la educación infantil y de la enseñanza fundamental en una perspectiva de educación que promueve el desarrollo humano. Dada la nueva comprensión del rol de la educación en la constitución de lo humano en cada uno de nosotros, la intencionalidad docente se hace esencial para enfrentar el reto planteado por Gramsci (1979) a la escuela y al maestro o maestra: formar a cada niño para ser un dirigente. Para eso, traigo algunas contribuciones de la teoría histórico-cultural para comprender el desarrollo humano y busco las implicaciones de esta concepción para la educación, lo que refuerza la importancia de la apropiación/construcción sustancial de una teoría pedagógica por parte de los docentes que pueda orientar su pensar y concretarse en forma de prácticas pedagógicas desarrolladas.

Palabras clave: Integración Educación Infantil y Enseñanza Fundamental. Articulación teoría y práctica. Teoría histórico-cultural. 
Introdução

Em primeiro lugar, dizer de onde falo e o ponto de vista de onde observo e avalio 0 trabalho docente. A percepção que tenho do papel do professor vem da teoria históricocultural acerca do desenvolvimento humano que, ao conceber o desenvolvimento psíquico como produto da atividade humana no meio cultural e histórico, concebe 0 professor como intelectual; percebe a atividade docente como a mais importante de nossa sociedade, uma vez que o professor é responsável por promover de forma intencional o processo de humanização das novas gerações. Do ponto desta teoria que tem em Vygotsky seu fundador, apoiado nos escritos de Marx, as nossas características humanas - nossa personalidade e nossa inteligência - são aprendidas, num processo de internalização de aptidões, capacidades, habilidades, valores que são vividos na convivência social. Esta compreensão de como se dá a formação do humano em nós seres que nos tornamos humanos por meio de nossa atividade, em condições materiais e concretas percebidas material e subjetivamente como um processo de educação - eleva a educação ao mais alto patamar da atividade humana. Como lembra Gramsci (1979), 0 papel do educador é formar cada criança para ser um dirigente.

Então, quando falo do professor, e especialmente do professor e da professora da infância de 0 a 10 anos, falo de um intelectual que pode organizar o trabalho docente de modo que cada criança se torne um dirigente, gente "pra brilhar e não pra morrer de fome", como queria Maiakowsky, nos versos cantados por Caetano Veloso.

Sendo este o nosso papel como professores e professoras, percebemos que receitas não cabem... a realidade contempla um forte componente de imprevisibilidade, tratamos com subjetividades que carregam suas histórias que condicionam a maneira como cada criança se relaciona com o mundo e se apropria dele formando para si as qualidades humanas. Por isso, precisamos analisar a complexidade do real para solucionar os problemas que surgem no horizonte do nosso trabalho e organizar as condições materiais de vida e educação que podem promover a formação e 0 desenvolvimento das máximas qualidades humanas em todas as crianças que frequentam nossas escolas da infância, independentemente de sua origem e situação de classe. 
Em segundo lugar, não há atividade criadora humana que não se paute pelo conhecimento profundo das leis e fenômenos que regem o campo onde a atividade se dá. Portanto, enfrentamos o desafio de conhecer as pesquisas e contribuições científicas em relação a como acontece o processo de humanização e o processo de conhecimento. Ao mesmo tempo, precisamos também nós, professoras e professores, participar ativamente da produção deste conhecimento. E, se isto é verdade para todos os campos do conhecimento humano, em relação à educação infantil, isto é ainda mais importante, pois parte do conhecimento que temos e que na sua quase totalidade tem orientado 0 pensar e 0 agir dos professores e professoras da infância, foi produzido sob um outro paradigma. Este paradigma olhava as crianças individualmente e não as crianças educadas coletivamente e percebia a criança como incapaz pois era vista numa perspectiva que a definia a partir das ausências de suas possibilidades quando comparadas aos adultos, portanto, tratava das negatividades e não das positividades do desenvolvimento infantil (VYGOTSKY, 1995).

Também é importante lembrar - para dimensionar a necessidade de nossos estudos - que a história da educação das crianças pequenas em espaços coletivos é curta... tem pouco mais de 100 anos e que o olhar científico às instituições de atendimento à infância é ainda mais recente, pois seu início em nosso país data dos anos 1970.

Disso decorre, por um lado, a necessidade de formação científica do professor e da professora a partir da recente produção de conhecimento sobre a infância e, por outro lado, a necessidade de formação da professora e do professor como pesquisadores, como produtores de conhecimentos sobre a infância.

Quando consideramos o quadro social, cultural e econômico do nosso país, me parece importante que nós, professoras e professores, também sejamos capazes de compreender a complexidade das relações sociais indo à essência das determinações das desigualdades sociais para compreender suas implicações na vida de meninos e meninas que frequentam nossas escolas e dimensionar o compromisso da escola e do trabalho docente humanizador frente à grande massa de crianças da classe trabalhadora que frequentam nossas escolas. Só assim poderemos superar os preconceitos do senso comum, combater os mitos que orientam nossas ações na escola e sair da condição de 
inocentes úteis para poucos e inúteis para muitos - para aqueles que precisam da escola para se inserir no mundo da cultura humana que é produzida por todos os seres humanos mas, de um modo geral, apropriada e usufruída por poucos. Entendo que esta é parte da complexidade que os cursos de formação básica e continuada têm que enfrentar.

Paralelo a isto, uma longa experiência com a formação inicial e continuada de professoras e professores para o trabalho com a infância têm me revelado a ausência de uma teoria pedagógica que oriente nossas escolhas docentes na organização do ambiente educativo de modo a promover a formação da personalidade das crianças em suas máximas possibilidades, como afirmam Gramsci (1979) e Vygotsky (2003) ser papel da escola e tarefa do trabalho docente.

Sem compreender que a formação das qualidades humanas - capacidades, aptidões, valores, hábitos, funções psíquicas como a memória, o controle da vontade, a fala, o pensamento, enfim, da personalidade - se dá condicionada pela qualidade das experiências vividas, isto é, pela qualidade do acesso à cultura e pelo lugar que a criança ocupa nas relações sociais de que participa, tendemos a pensar que as crianças são o que nasceram para ser. Deste ponto de vista, as crianças apenas revelam tendências hereditárias frente às quais a escola não tem o que fazer. Essa visão naturalizante do processo de formação da pessoa imobiliza o trabalho docente e empobrece a experiência vivida na escola. Some-se a isso, a concepção de criança incapaz que vem do mesmo olhar não informado pela ciência - seja no campo da psicologia, da antropologia, da neurologia - que produz uma visão negativa das capacidades das crianças pequenas, orientada para as ausências e as incapacidades das crianças frente aos adultos, como vimos acima.

Por outro lado, compreender o processo de formação da personalidade como um processo de educação eleva a atividade educativa para a esfera da atividade humana complexa, que requer para sua efetivação, uma lógica distinta daquela empregada na vida cotidiana. A reflexão típica dessa esfera complexa da atividade humana, assim como a atitude de estranhamento, crítica, curiosa frente ao ato pedagógico conduzem à necessidade de observar as condições objetivas e subjetivas do processo como as crianças aprendem nas diferentes idades, de conhecer as regularidades de seu desenvolvimento e as possibilidades concretas de organização do espaço, gestão do 
tempo, estabelecimento de relações e oferta de atividades encantadoras que inaugurem para as crianças o desejo humanizador de conhecer o mundo. Importante lembrar que 0 ato pedagógico é sempre novo porque fruto de um protagonismo complexo que envolve a criança como sujeito do ato de aprender, a professora ou o professor como sujeito da organização do ambiente educativo que promova o protagonismo infantil e a cultura - 0 meio - como repositório e fonte das qualidades humanas criadas ao longo da história.

A teoria histórico-cultural acerca do desenvolvimento humano oferece elementos para orientar o pensar e 0 agir docentes na perspectiva de formar "gente pra brilhar e não pra morrer de fome" sem abreviar a infância, ao contrário, incentivando 0 aprofundamento das atividades práticas, plásticas e lúdicas (ZAPOROZHETS, 1987). Apresentar uma visão desta teoria sob a forma de implicações pedagógicas para a formação de professores para o trabalho com a infância de 0 a 10 anos é o objetivo desta minha reflexão. Por isso, frente aos muitos desafios para a formação de professoras e professores intelectuais, entendo que ensinar uma teoria pedagógica que fundamente práticas humanizadoras e desenvolventes, assim como as formas de sua concretização, é o primeiro deles.

Vixe... mais teoria? J á não tem teoria demais na formação de professores?

É atitude comum, e não apenas entre professoras e professores, mas também entre profissionais ligados às secretarias de educação e ao próprio ministério da educação, a concepção de que os nossos cursos de formação de professores estão repletos de teoria e que precisamos investir nas práticas. Isso porque entendem a teoria como um blábláblá, um discurso sobre questões entendidas como desvinculadas da prática docente. Cometem um equívoco ao confundir teoria com discurso sobre teoria. Pois, na mesma linha do ditado popular que afirma que a teoria, na prática é outra, desmerecem a teoria deixando subentendido que na prática ela não funciona. Ora 0 problema está em que sem adotar uma teoria que seja um conjunto de elementos que explicam um processo - em nosso caso específico, o processo pedagógico - e sem ter elementos mediadores que possibilitem a concretização desta teoria, transitam no nível do anuncio de uma teoria, sem, no entanto, tratar dela especificamente. Deste modo, 0 que acontece não é que a teoria não funcione na prática, pois, neste caso não se tem uma 
teoria, mas um discurso sobre a teoria. Nesta condição de não ter instrumentos que concretizem a teoria, anuncia-se uma teoria, mas a prática acaba sendo orientada pelo senso comum. Quem fala da teoria, apenas a anuncia, mas não a concretiza, pois não conhece instrumentos que a concretizem, não reflete e não busca suas implicações pedagógicas.

Estes tempos que vivemos já decretaram que a professora e o professor têm que estudar sempre, procurar conhecer sempre e cada vez mais sobre a especificidade do aprender dos bebês e das crianças pequenas. Para isso, conhecer como se dá o processo de desenvolvimento humano é condição para a adoção de uma teoria pedagógica que oriente nosso pensar e agir na educação infantil. É a partir da compreensão de como acontece o desenvolvimento humano na infância que podemos dimensionar o papel da educação nesse desenvolvimento, o papel da escola, o lugar e o papel do professor e da professora, o lugar que a criança deve ocupar no processo de aprender, o lugar da cultura - isto é, de tudo o que viemos criando ao longo da história humana, sejam hábitos e costumes, objetos, linguagens, a língua falada, a ciência e as técnicas - para promover 0 desenvolvimento humano. A partir daí é que poderemos intencionalmente organizar 0 trabalho escolar, isto é, o espaço e os materiais, programar as formas de gestão do tempo, cuidar das formas como acontecem as relações - entre adultos e crianças, entre as crianças de mesma e diferentes idades, entre os adultos da escola, entre a escola e as famílias, entre a escola e a comunidade - e organizar as atividades vividas com as crianças de modo que elas possam ser sujeitos ativos, protagonistas neste processo.

Uma teoria psicológica - que problematize o desenvolvimento psíquico e cultural - é, por tudo isso, ponto de partida para a constituição de uma teoria pedagógica que oriente diariamente nosso pensar e agir na escola: que nos ajude nas tomadas de decisões, na solução dos problemas e na condução da vida na escola.

A maior parte dos cursos de formação hoje ainda não discute a especificidade da infância de modo a desvelar a complexidade deste processo em que a educação de um modo amplo e a escola de modo específico têm um papel essencial para a configuração da inteligência e da personalidade. Em geral, com a criação de disciplinas voltadas para a pequena infância nos cursos de pedagogia, vimos, de um modo geral, apenas a mudança 
nos títulos das disciplinas dos cursos de formação de professores e professoras para as séries iniciais". Nesse sentido, pouco se tem feito para superar a ideia de que o professor e a professora da educação infantil não dão aulas, as crianças pequenas e pequenininhas quando vêm para a escola infantil não viram alunos e na escola da infância não temos sala de aula: bebês e crianças continuam crianças ao passar a frequentar a educação infantil, professor e professora não dão aula, mas organizam a vida das crianças que deve continuar livre para brincar, explorar e conhecer num ambiente intencionalmente organizado para provocar sua curiosidade, sua exploração e conhecimento do mundo e, deste ponto de vista, os espaços externos do prédio da escola são tão importantes quanto os internos e entre os espaços internos não há uma hierarquia e devem ser usados de forma múltipla e criativa.

Do ponto de vista da lógica que orienta nosso pensar e agir como professores e professoras: o trabalho com a infância pouco se profissionalizou, em grande parte continua centrado numa visão cotidiana, oriunda da experiência doméstica do professor ou da professora e ainda com uma presença quase absoluta de mulheres, o que fomenta uma continuidade da educação espontânea da família e seguindo seus mesmos equívocos: subsistem nas formas históricas do trabalho feminino, a mesma divisão de gênero, as mesmas estratégias de controle, os mesmos preconceitos silenciosos contra as crianças que as afastam da participação nas decisões, nas escolhas, nas soluções de problemas, da organização da vida na escola.

Reforçando, por um lado, a ausência de uma teoria que oriente 0 fazer dos professores e professoras, e, por outro lado, a presença do senso comum, temos uma cultura escolar que naturaliza os processos em nome do "sempre foi assim", o que para bom entendedor significa também que "sempre será". Escola como lugar onde se dá aula, onde 0 professor fala e 0 aluno escuta, o professor controla e 0 aluno obedece, 0 professor decide e os alunos fazem o que o professor manda. $E$ isto com um agravante quando se trata da educação infantil - ou dois. Como sabemos pouco e refletimos pouco sobre a especificidade do aprender na infância, as "aulas" que em geral são propostas beiram ao absurdo tanto para as crianças como para os professores e professoras: como 0 que se idealiza em geral não corresponde às formas como as crianças pequenas conhecem o mundo (todas as crianças fazendo a mesma atividade, no mesmo ritmo, 
interessadas na mesma atividade, sentadas ao redor de mesas, em silêncio, seguindo ordens para realização da "atividade"), o resultado é que os professores e professoras passam a maior parte do tempo tentando conseguir atenção, silêncio, ritmo padronizado e condutas padronizadas. Com isso perdem um tempo precioso de vivência coletiva no que poderia ser um ambiente que alimentasse e deixasse fluir a energia das crianças.

Falta, portanto, uma teoria para orientar nosso pensar e o agir docentes que supere o senso comum que trata o fazer educação como atividade cotidiana e não como ciência, uma teoria necessariamente ancorada na compreensão do processo de desenvolvimento humano, isto é, no processo de humanização, na compreensão de como as crianças aprendem.

Por que a Teoria Histórico-Cultural?

Carl Sagan, astrônomo estadunidense que dedicou sua vida à produção do conhecimento e à divulgação da ciência, dizia que frente a duas teorias, mesmo que ainda não tivessem sido comprovadas, ele adotaria a que fosse mais progressista. Penso que ele tinha razão. Adotar uma teoria com uma visão positiva e desenvolvente do ser humano seria uma razão para escolher a teoria histórico-cultural. Mais ainda quando esta teoria, ademais de progressista tem sido fartamente comprovada por estudos no seu campo (vide estudos de Vygotsky e todos os outros pesquisadores que se juntaram ao que em geral se chama de Escola de Vygotsky), inclusive por estudos em outros campos do conhecimento como a pedagogia e a própria medicina com as neurociências.

Outro argumento para a adesão à abordagem histórico-cultural para olhar 0 processo pedagógico e planejar sua organização é o fato de que esta é uma abordagem teórica do desenvolvimento humano que implica a educação e os processos educativos escolares.

Aprendemos a pensar o desenvolvimento da inteligência e da personalidade humana como algo que acontece naturalmente à medida que a criança cresce, a partir do desenvolvimento biológico da criança. Diferente disso, o enfoque histórico-cultural vê o ser humano e as características humanas como produtos da história que o próprio ser humano criou e cria. Em outras palavras, juntamente com a criação dos objetos, dos 
instrumentos, da ciência, das formas de relacionar-se, dos valores, dos costumes, da lógica, das linguagens o ser humano foi se criando.

O enfoque histórico-cultural vê, portanto, o humano ou as qualidades humanas como produção humana. E é só ol har para os nossos antepassados, na idade da pedra ou mesmo na idade média para concordarmos em que as qualidades humanas foram sendo criadas ao longo da história no mesmo processo que os homens e as mulheres foram criando os objetos da cultura material e não material.

Vygotsky, ancorado em Marx, percebeu, além disso, que essas faculdades (a linguagem, o pensamento abstrato, a memória voluntária, os sentimentos, as percepções, a atenção voluntária, as habilidades, as capacidades, etc.), criadas ao longo da história humana, não se fixam geneticamente, mas se fixam nos objetos externos da cultura material e não-material. Cada criança que nasce precisa se apropriar desses objetos da cultura - aprender a utilizá-los - para reproduzir para si as habilidades e capacidades humanas fixadas neles. E é só pensarmos em personagens do cinema como Kaspar Hauser $^{2}$, Nell ${ }^{3}$ e nas meninas iranianas personagens de A Maçã ${ }^{4}$ para concordarmos também com essa ideia de que, ao nascer, as novas gerações encontram um mundo pleno de objetos e instrumentos, de signos que precisam aprender a utilizar e ao aprender a utilizá-los se apropriam também das faculdades humanas necessárias ao seu uso e que estão fixadas nesses produtos da cultura. E sem a presença da cultura, não há desenvolvimento humano. Como afirma Vygotsky (2010), "a cultura é a fonte das qualidades humanas". Vygotsky demonstrou que antes de uma qualidade humana ser interiorizada pela criança, ela é vivida coletivamente (socialmente). Quer dizer, antes de ser interna, uma característica humana é externa, vivida nas relações sociais das crianças com parceiros mais experientes. Para aprender a utilizar os objetos da cultura - do garfo à bicicleta, da leitura à solidariedade - temos que aprender sempre com os outros. Ou seja, o processo de apropriação da cultura como das faculdades humanas precisa ser aprendido coletivamente com parceiros mais experientes. Não se trata, pois, de uma relação imediata entre a criança e o objeto a ser conhecido, mas uma relação mediada socialmente, coletiva. Por isso a relação das novas gerações com a cultura, que constitui

\footnotetext{
2 O Enigma de Kaspar Hauser, filme de Werner Herzog, 1974.

${ }^{3}$ Nell, filme de Michael Apted, 1994.

${ }^{4}$ A Maçã, filme de Samira Makhmalbaf, 1998.
} 
o processo de aprendizagem das características humanas, é sempre um processo de educação.

Como afirma Marx (2006), as percepções humanas, o sentido ético, estético, a moral, as emoções, as capacidades, as aptidões, o sentimento, a vontade, 0 pensamento... tudo no ser humano resulta de sua atividade social com os objetos da cultura em processos de vida e educação.

Assim, enquanto para as concepções anteriores a Vygotsky, o processo de desenvolvimento psíquico (quer dizer de desenvolvimento da inteligência e da personalidade) aconteceria de certa forma de maneira independente do processo de educação, para Vygotsky, a teoria do desenvolvimento humano é essencialmente uma teoria da educação. Desde as primeiras semanas de vida do ser humano manifesta-se a lei geral do desenvolvimento psíquico: as ações externas vividas socialmente vão sendo interiorizadas pelo sujeito e vão se tornando ações internas.

Então, para o enfoque histórico-cultural, os aspectos biológicos são essenciais mas não são suficientes para mover o desenvolvimento psíquico que se configura como desenvolvimento cultural. 0 que move o desenvolvimento é a atividade do sujeito, atividade esta que é coletiva, mediada por um parceiro mais experiente - que, na escola, é, em última instância, o professor; mas, não apenas ele: também os outros profissionais da escola e as outras crianças de mesma e de maior idade são parceiros fundamentais para a atividade.

Se observarmos uma criança em seus primeiros dias de vida, perceberemos que 0 próprio estabelecimento de relações com os outros e com o mundo é produto da educação. 0 adulto é fundamental para educar a atenção e a concentração dos bebês. É 0 adulto - que se aproxima dele para cuidar e que fala com o bebê como se ele já fosse capaz de responder - que ensina o bebê primeiro a concentrar a atenção no adulto que fala, depois a gostar dessa relação de ter alguém Ihe dando atenção, e finalmente a buscar essa relação... Da mesma forma se dá com a fala e com a formação de todas as funções psíquicas superiores como a memória voluntária, o pensamento verbal, 0 controle da própria conduta. Essas funções, antes de serem internas à cada criança, são sempre e inicialmente exercitadas como ações externas. E por isso a história do 
desenvolvimento de cada criança é uma história de sua relação inicialmente com o adulto que a cuida e educa.

Deste ponto de vista, a educação tem um caráter essencialmente humanizador. Em outras palavras, ao demonstrar que as pessoas aprendem a ser o que são a partir de sua atividade em condições materiais e concretas de vida, ao apontar o processo de educação como responsável pela humanização, isto é, pela formação das funções ligadas à inteligência e à personalidade, a abordagem histórico-cultural aponta para a educação - seja familiar, seja escolar - um novo e essencial papel antes não percebido anteriormente para a educação: a formação das qualidades humanas, a educação da personalidade e da inteligência.

Como afirma Leontiev (1978b, p. 272),

As aquisições do desenvolvimento histórico das aptidões humanas não são simplesmente dadas aos homens nos fenômenos objetivos da cultura material e espiritual que os encarnam, mas são aí apenas postas. Para se apropriar destes resultados, para fazer deles as suas aptidões, 'os órgãos da sua individualidade', a criança, o ser humano, deve entrar em relação com os fenômenos do mundo circundante através doutros homens, isto é, num processo de comunicação com eles. Assim, a criança aprende a atividade adequada. Pela sua função, este processo é, portanto, um processo de educação.

Nesse processo, a escola tem um papel igualmente fundamental: organizar intencionalmente as condições materiais e concretas da vida na escola para promover a atividade das crianças e por meio de sua atividade num ambiente organizado para isso, a formação das melhores qualidades humanas. Em outras palavras, muda o papel da escola, especialmente na educação infantil e muda no sentido de ampliar a responsabilidade da escola - que passa a ser a de ensinar e pensar, muito mais que treinar coordenação motora ou ensinar cores, formas, profissões, ou - muitas vezes na ausência de algo considerado importante a fazer com as crianças - antecipar o ensino da escrita, o que pode ser ainda mais danoso para a formação de crianças leitoras e produtoras de texto.

Muda também a compreensão do papel do professor nesse processo educativo: de secundário, facilitador de um desenvolvimento já dado ao sujeito no nascimento, passa a ser essencial, uma vez que o professor passa a ter o papel de formar e desenvolver intencionalmente as características humanas nas novas gerações, ou seja, formar e desenvolver a personalidade e a inteligência das crianças. No entanto, muda também 0 
lugar que o professor e a professora ocupam no processo educativo. Frente à compreensão de que as crianças aprendem quando realizam uma atividade ${ }^{5}$, o papel do professor e da professora passa a ser o de organizar as condições concretas para que as crianças se envolvam em atividades promotoras de conhecimento do mundo e de desenvolvimento humano.

Desse ponto de vista, um elemento chave para o trabalho docente é a compreensão de que à medida que as crianças vão formando e desenvolvendo níveis mais elaborados de consciência, vão buscando níveis mais elaborados de atividade - o que, por sua vez, amplia seu desenvolvimento da consciência. Como lembra Vygotsky, cada idade possui características que configuram o nível de formação e desenvolvimento da consciência da criança que pode ser percebida em sua relação com o meio - objetos, pessoas, situações. E esta consciência - que a teoria histórico-cultural considera como produto das "mudanças físicas e sociais" vividas pela criança (VYGOTSKY, 1996, p. 262) é a expressão integral das características mais importantes da personalidade da criança.

A dinâmica do desenvolvimento humano na infância envolve períodos estáveis e momentos de ruptura - que configuram os saltos no desenvolvimento, ou seja, a ruptura com o período anterior e a entrada numa nova idade. Entre 0 e 10 anos, podemos perceber esses períodos estáveis como sendo a primeiríssima infância (o primeiro ano de vida), a primeira infância (entre 1 e 3 anos), a idade pré-escolar (entre 3 e 6 anos) e a idade escolar (a partir dos 6 anos). "Ao final de uma idade, a criança se torna em um ser totalmente distinto do que era no início dela" (VYGOTSKY, 1996, p. 265). Por isso, nós, adultos, ficamos atentos às mudanças das crianças entre essas idades: devido às novas formações que surgem ao final de cada idade, muda a consciência da criança e com isso muda sua forma de perceber e lidar com o ambiente externo e consigo mesma: as rupturas com o comportamento anterior e a necessidade de novos espaços para crescer são inevitáveis e devem ser intencionalmente acolhidas e orientadas pelos adultos.

\footnotetext{
${ }^{5}$ Atividade no contexto da teoria histórico-cultural não tem o sentido do senso comum presente na escola de um modo geral, como sinônimo de fazer algo, em geral sob a orientação e ordem de alguém. Para a Teoria histórico-cultural, atividade é algo em que a criança se envolve profundamente com o corpo, a mente e a emoção, e motivada justamente pelo resultado do processo. Esse envolvimento, em geral, requer a participação da criança nas decisões, no planejamento, na vida da escola; envolve a escuta do professor e da professora em relação aos motivos e desejos de saber das crianças.
} 
Entre 0 e 10 anos, os períodos estáveis configuram formas de relação da criança com o mundo que a rodeia - o meio físico e social, a cultura - chamadas de atividade principal: a linguagem por meio da qual, a criança em cada idade melhor se relaciona com o meio e se apropria dele e forma para si as qualidades humanas. No primeiro ano de vida, a atividade principal dos bebês é a comunicação emocional com os adultos que cuidam e educam o bebê. Na primeira infância, essa atividade se configura como manipulação de objetos ou atividade livre e autônoma com objetos. Na idade pré-escolar, é a brincadeira de papeis sociais e na idade escolar, a atividade de estudos.

Essencial é perceber que é a mesma criança que caminha pelas diferentes formas de relação com o mundo, a partir da integralidade de sua experiência que condiciona sua consciência. A transição de uma idade a outra é comandada pela própria criança e cabe à escola acompanhá-la propondo experiências cada vez mais desafiadoras e desenvolventes. Isto é o oposto do que vemos acontecer na escola em que as mudanças são impostas às crianças sem base no conhecimento acerca da dinâmica do desenvolvimento humano na infância e fundamentada apenas na cultura escolar autoritária estruturada na tradição do senso comum, ou seja, sem base científica.

Antes de entrarmos na discussão específica deste texto acerca da transição da educação infantil para o ensino fundamental, cabe lembrar ainda que, com o enfoque histórico-cultural e frente à compreensão de como a criança aprende e se humaniza, muda igualmente, e de forma radical, nossa concepção de criança e de seu papel no processo de seu desenvolvimento. De ser passivo, passa a ser ativo, capaz de aprender desde muito pequenininha com as relações sociais que vive, capaz de atribuir sentido às situações que experimenta. Para o enfoque histórico-cultural, a aprendizagem move 0 desenvolvimento e esta acontece quando a criança está motivada, afetada pela atividade que realiza.

Os motivos, as necessidades humanas, assim como as funções psíquicas são aprendidos com as experiências vividas. Assim, é papel do professor e da professora criar nas crianças necessidades humanizadoras (que são diferentes das necessidades que 0 capitalismo cria. A TV cria a necessidade de consumir e de ter, mas não cria necessidades humanizadoras que provocam nas novas gerações o desenvolvimento de características humanas mais sofisticadas: a necessidade de saber, de ser solidário, de novos prazeres 
vinculados à observação de uma obra de arte, à audição de uma música ou de um espetáculo de dança ou teatro, o prazer de ler). À escola e ao trabalho docente cabe a criação destas necessidades e prazeres. Isto significa que é papel da escola - e do trabalho docente que torna real e concreto este papel - não apenas apresentar o mundo da cultura, mas apresentá-lo de forma tal a encantar as crianças, de forma a criar nelas a vontade de conhecer mais e mais este mundo da cultura humana que a rodeia. Em relação ao lugar da cultura no processo de conhecimento humano, Vygotsky (2010) afirma que "a cultura é a fonte das qualidades humanas". O que o autor quer dizer com isso? Conforme esclarecem Pederiva, Almeida e Mello (2017), com cada objeto material (como as ferramentas, as casas, os livros) ou não material (como as peças de teatro, as músicas, as danças, a literatura, hábitos e costumes, a ciência e as técnicas, a língua, as formas de pensar) criado ao longo da história, os seres humanos criaram e continuam a criar também as aptidões, as habilidades, as capacidades, as funções psíquicas superiores necessárias à criação e ao uso destes objetos. Essas funções psíquicas superiores ficam como que guardadas nestes objetos da cultura e à medida que as novas gerações, por meio das gerações mais velhas, aprendem a usar esses objetos da cultura, aprendem também as aptidões e as funções psíquicas postas nesses objetos. Em outras palavras apropriam-se delas. Por isso, a cultura humana social e historicamente acumulada é o repositório das qualidades humanas.

Vale insistir que, como afirma Leontiev (1978b), esse processo é sempre ativo do ponto de vista das novas gerações que estão formando e desenvolvendo para si as qualidades humanas. Este processo de humanização por que passa cada criança - isto é, por meio do qual ela se humaniza - acontece por meio de sua atividade na convivência social em que vai aprendendo a usar a cultura - que é tudo o que os seres humanos criaram e continuam a criar ao longo da história, os hábitos e costumes, a ciência, a língua, a arte, os objetos.

E, para Vygotsky (2010), apresentamos a cultura em suas formas mais elaboradas paras as crianças, diferente do que tradicionalmente se faz na escola quando se pensa que devemos "respeitar o nível de desenvolvimento das crianças" e acabamos por apresentar o simples, o simplificado, o pouco elaborado acreditando que as crianças "não são capazes" de se relacionar com as formas mais elaboradas da cultura e atribuir-Ihe um 
valor, um sentido. Ao contrário disto, nas formas mais elaboradas da cultura estão "guardadas" as formas mais elaboradas da atividade humana e com elas o exercício das formas mais sofisticadas das funções psíquicas superiores. Cabe, pois, à escola a apresentação deste mais elaborado às crianças de diferentes idades. (FARIAS; MELLO, 2010).

Para Vygotsky (1995), portanto, o trabalho docente de qualidade concebe a infância como o tempo de formação e desenvolvimento de qualidades humanas que não sendo hereditárias precisam ser formadas na atividade social da criança: funções sofisticadas como a percepção categorial, a memória, a fala, o pensamento, a imaginação o autocontrole da vontade, uma compreensão de si - funções que, de um modo geral, são invisíveis ao olhar menos atento.

Para Vygotsky (1988), o trabalho docente é desenvolvente, quer dizer, faz exercitar as funções psíquicas superiores nas crianças e, assim, movimenta 0 desenvolvimento; faz avançar o nível de desenvolvimento humano já alcançado pela criança. Deste ponto de vista, este trabalho docente incide na zona de desenvolvimento próximo ou iminente da criança provocando avanços nas possibilidades de atividade da criança. Por isso, o trabalho docente desafia a criança a fazer sozinha o que ela já sabe e a pedir ajuda para o que ainda não consegue fazer sozinha. Assim, o trabalho docente não se confunde com treino ou tarefa repetitiva, mas desafia o pensamento, estimula a solução de problemas enfrentados pelo grupo de crianças, incentiva a iniciativa, a curiosidade, a autonomia e a agência das crianças. Para agir como o parceiro mais experiente e promover a agência das crianças, o professor e a professora precisam conhecer o nível de desenvolvimento já alcançado pelas crianças (ou seja, aquilo que as crianças são capazes de fazer sozinhas) e o nível de desenvolvimento próximo ou iminente (ou seja, aquilo que as crianças são capazes de fazer com alguma ajuda ou cooperação do professor, da professora ou dos colegas). Esse conhecimento vem da observação - da escuta - das crianças.

É, portanto, a partir de um olhar teórico ao desenvolvimento humano na infância que se planeja a organização do espaço e dos ambientes da escola, seus materiais; que se planeja a gestão do tempo - e se elegem as atividades que serão centralizadas no docente, as que terão gestão compartilhada entre adultos e crianças e as atividades livres 
que serão geridas pelas crianças sem a intervenção direta do adulto. É com base na teoria que se definem as formas das relações entre adultos e crianças, entre as crianças de mesma e diferentes idades, assim com as relações entre os próprios adultos da escola, da escola com as famílias e a relação da escola com a comunidade e com a cidade. É também com um olhar na teoria que se definem as experiências que serão organizadas para promover nas crianças a formação das máximas qualidades humanas: como se planeja promover o exercício do pensamento, da iniciativa, da autonomia, etc.

\section{A Transição Entre a Educação Infantil e o Ensino Fundamental}

Considerando o que viemos discutindo até aqui, isto é, buscando fundamentar o trabalho docente na abordagem histórico-cultural, nos parece que na educação e no ensino fundamental - e na passagem das crianças de um nível a outro - será fundamental acolher e respeitar a voz das crianças, sua agência, suas histórias e possibilidades. Nesse sentido, a organização dos tempos, espaços e materiais e a proposição de vivências precisam considerar que as rupturas com o comportamento e com a forma anterior de atividade da criança são dadas pela criança e não impostas pelos adultos e que estes são processos que, como o próprio sentido da palavra processo indica, não acontecem de um dia para o outro, mas são produtos de acúmulo de experiências que acontecem num tempo. Nesses momentos, assim como a comunicação emocional - atividade principal no primeiro ano de vida - não acaba na passagem à primeira infância, mas vai aos poucos se tornando secundária, devido à nova configuração da consciência do bebê e de sua atividade, e da mesma forma como na passagem da primeira infância para a idade préescolar a atividade autônoma com objetos não deixa de acontecer quando o brincar se torna a atividade principal, também na passagem da idade pré-escolar para a idade escolar, a brincadeira de papeis sociais não cessa abruptamente, mas vai sendo aos poucos substituída pela atividade de estudos, quando o estudo é apresentado à criança de forma a criar nela um novo prazer, um novo motivo e uma nova necessidade de saber.

Por isso, uma proposta pedagógica que contemple a criança em sua integralidade, como pessoa vivendo uma experiência que promove seu desenvolvimento psíquico e cultural crescentes, não desconsidera a importância do brincar, a integração de saberes de diferentes campos do conhecimento, as linguagens de expressão das crianças por 
meio das quais objetivam - expressam - sua compreensão do mundo em diálogo permanente com seus processos de apropriação - de aprendizagem da cultura histórica e socialmente acumulada. Em outras palavras, uma tal proposta pedagógica não desconsidera que a vida é o motor do desenvolvimento psíquico e cultural. Nesse sentido, transitar da educação infantil para o ensino fundamental não implica que a criança deixe de brincar, nem se divida em corpo e mente ao ingressar no Ensino Fundamental. Ao contrário, ela continua a ser criança e deve ser compreendida em sua integralidade tendo oportunidades de avançar em seu conhecimento da cultura sem abandonar a infância.

Por isso, em lugar de as crianças transformadas precocemente em alunos, é possível criar processos de aprendizagens significativos e socialmente relevantes que estejam presentes igualmente na educação infantil e no ensino fundamental, de modo a cuidar e educar crianças que pensam e agem de forma cada vez mais curiosa e autônoma no mundo.

A ideia que emerge da abordagem histórico cultural - e há muito discutida a partir do bom senso pedagógico - de que as experiências vividas pelas crianças no presente não são preparatórias de etapas futuras, mas importam para o tempo presente para a constituição da pessoa com as máximas qualidades humanas, fundamenta uma atitude de respeito aos tempos e modos de viver a infância e cria bases sólidas para a vida futura justamente por que não antecipa processos que transformam as crianças pequenininhas em pré-escolares e os pré-escolares em escolares, que não sonega à criança o direito de viver a infância e constituir sua personalidade. Conforme análise de Reinach (2013), no momento em que a ciência descobre que ao longo dos últimos milênios vem ocorrendo um progressivo retardamento do amadurecimento do cérebro humano - devido ao crescimento do alcance do conhecimento - e que este retardamento no desenvolvimento do cérebro é condição para dar conta da sofisticação das funções psíquicas exigidas pelo desenvolvimento histórico e cultural alcançado por nossa sociedade, o abreviamento da infância que se concretiza em escolas de educação infantil é um contrassenso.

Assim, rever a cultura escolar que apressa o término da infância e aprisiona a criança em nome da potencialização do desenvolvimento numa "corrida pra lugar 
nenhum"6 é condição para a formação de crianças para pensar. Para isso, como afirma 0 documento Currículo Integrador da Infância Paulistana (SÃO PAULO, 2016, p. 17),

Ao longo da Educação Infantil e do Ensino Fundamental, bebês e crianças precisam de tempo e vivências para ampliar suas formas de ver, conceber e expressar 0 mundo através das diferentes linguagens que integram arte e ciência no complexo processo de apropriação e construção de conhecimento que envolve curiosidade, observação, atenção, percepção, pensamento, investigação, interpretação, criação de hipóteses, imaginação e elaboração de teorias explicativas daquilo que vivem e observam. Tudo isso resulta em significativas aprendizagens que só acontecem pela atitude ativa da criança no meio social quando é tratada como sujeito capaz de realizar tudo isso.

\section{E continua,}

Nessa perspectiva, o desafio que se apresenta é o de superar a hierarquização e o caráter instrucional que privilegia a fala de professoras e professores sobre 0 conhecimento, superar os treinos de linguagem escrita e o silenciamento das demais linguagens e conteúdos, superar a lógica da divisão de trabalho fabril presente na escola e que separa, de um lado, educadora e educador que pensam e, de outro lado, as crianças que não são chamadas a pensar, mas apenas a executar o que foi pensado para elas. Trata-se de promover, no dia a dia da Educação Infantil e do Ensino Fundamental, o protagonismo das educadoras e dos educadores como organizadores de experiências em que bebês e crianças na educação infantil e no ensino fundamental são igualmente protagonistas [brincantes, artistas e cientistas] que pensam, projetam, agem, descobrem, criam e recriam o mundo, e expressam tudo isso de forma ativa, rica e autoral. (SÃO PAULO, 2016, p.17-18).

Como pressuposto fundamental desta transição, o trabalho docente se organiza sem rupturas, num conjunto de práticas sequenciais que advêm do compartilhamento das concepções discutidas ao longo deste nosso texto: de educação, escola, processo de conhecimento, infância, criança e de práticas que medeiam estas concepções. Isto implica o conhecimento mútuo de profissionais e práticas. Uma maneira de garantir este compartilhamento de concepções e práticas são as atividades conjuntas que congreguem professores e professoras de ambos os seguimentos e as próprias crianças. Algumas das boas práticas observadas em escolas da Rede Municipal de São Paulo incluem, por exemplo, crianças do ensino fundamental que leem para crianças da educação infantil prática esta que envolve articulação entre os docentes, visita aos espaços, participação nas rotinas de um e outro segmento.

Uma maneira de iniciar essa articulação com o ensino fundamental pode resultar da iniciativa da escola de educação infantil de apresentar a escola de ensino fundamental

\footnotetext{
${ }^{6}$ Referência ao movimento "Race to nowhere", de professores, alunos e pais estadunidenses contra 0 abreviamento da infância e a disputa por "chegar primeiro" não se sabe exatamente onde que se instala na escola - neste mundo em constante mudanças e com quase 7 bilhões de pessoas.
} 
às crianças que no ano seguinte a frequentarão. Ao longo deste último ano das crianças na educação infantil, visitas periódicas da turma podem ser organizadas para a realização de atividades planejadas conjuntamente pelas professoras da educação infantil e do primeiro ano do ensino fundamental por meio das quais as crianças de ambas as turmas possam se conhecer, as crianças da educação infantil possam conhecer o espaço e as rotinas do ensino fundamental e também se dar a conhecer à nova professora que poderá acolhê-las no ano seguinte.

Seja como iniciativa individual de uma turma, ou como iniciativa de escolas ou de uma rede inteira, este compartilhamento que envolve conhecimento e escuta resulta em aprendizagens docentes que possibilitam relações cuidadosamente pensadas no ensino fundamental para receber e acolher as crianças da educação infantil que chegam muito mais cedo no ensino fundamental; uma organização dos espaços e materiais mais intencional e articulada às necessidades e ao enriquecimento das necessidades das crianças; formas de gestão do tempo que contemplem os tempos diferentes das crianças; a proposição e organização de vivências que encantem as crianças tanto na educação infantil quanto no ensino fundamental, e, neste sentido, que lhes eduque a atenção e 0 interesse. Fundamental considerar sempre que, à medida que crescem, as crianças precisam de espaço para crescer, requerem relações cada vez mais autônomas e contato cada vez mais amplo com a cultura. Pela própria relação entre aprendizagem e desenvolvimento apontada pela abordagem histórico-cultural (VIGOTSKII, 1988) vivências desafiadoras devem fazer parte da vida das crianças na educação infantil e no ensino fundamental. E pelo princípio da atividade, as crianças precisam ser sujeitos de seus processos e, para isso, precisam de tempo para pensar e resolver problemas. Nesta nova cultura escolar, professoras e professores apresentam o mundo e acompanham a criança em atividade, oferecem ajuda e a incentivam a experimentar, a buscar explicação aos fatos, a investigar, a planejar, a solucionar problemas, enfim, a exercitar 0 pensamento como ser inteiro em seu encontro com o mundo. Em outras palavras, 0 protagonismo do professor e da professora não se impõe ao protagonismo das crianças; ao contrário, o protagonismo dos adultos promove o protagonismo das crianças, considerando que o processo de ensinar e aprender acontece por meio de relações de comunicação, de ações em comum entre as próprias crianças e, também, entre crianças e 
adultos. Assim, professor e professora organizam vivências, situações em que as crianças sejam sujeito e todos pensem juntos para aprender a pensar sozinhos, resolvam problemas como grupo para aprender a resolvê-los sozinhos, e da mesma forma decidam juntos, escolham juntos, planejem juntos, avaliem juntos, tomem iniciativa, proponham juntos o que fazer na escola. 0 envolvimento e a participação das crianças, na educação infantil e mais ainda no ensino fundamental, contribuem fortemente para mudar a forma artificial, fragmentada e desligada da vida como a escola tem tradicionalmente apresentado o conhecimento para as crianças.

\section{A Atividade de Estudo7 no Ensino Fundamental}

A atividade de estudo, que conduz o processo de aprendizagem, se constitui, em primeiro lugar, quando os alunos têm uma necessidade e um motivo para realizar 0 estudo, uma vez que aprender envolve um ato criativo de transformação do objeto no conhecimento deste objeto. 0 processo de aprender exige a atividade humana em sua plenitude. Não basta a presença física do aluno: também sua atividade intelectual e seu envolvimento emocional estão presentes na atividade. A presença de necessidades e motivos da criança no ato pedagógico possibilitam o ato criativo, a experimentação, 0 levantamento de hipóteses, o agir frente ao objeto de conhecimento. Por isso, parafraseando Davidov (1988), quando a professora ou o professor criam sistematicamente situações que exigem das crianças a experimentação para a obtenção de conhecimentos sobre o objeto, as crianças iniciam a atividade de estudo.

Esta atitude frente ao conhecimento não acontece só no ensino fundamental, mas pode se iniciar mais cedo. Na educação infantil, as crianças não querem só brincar: também querem saber se os dinossauros podem voltar, se os terremotos podem acontecer em sua região, quanto tempo vivem as formigas, quantos tipos de inseto existem no mundo e se é verdade que na China as pessoas comem insetos. Quanto maior

\footnotetext{
${ }^{7} 0$ termo atividade é presença constante no vocabulário escolar brasileiro e, por isso, cabe retomar novamente aqui 0 sentido bastante distinto de atividade na perspectiva histórico-cultural. Leontiev (1978a), ao descrever a estrutura concreta da atividade humana, indica que esta se compõe de necessidade e motivo, objetivo, condição e meios para sua realização. Realizar uma atividade implica se dar conta dos seus componentes, pois só assim o sujeito da atividade pode perceber a transformação da realidade que ele realiza por meio da atividade, o que possibilita a transformação de si mesmo.
} 
o conhecimento de mundo das crianças e quanto mais acolhedora for a relação com os adultos que as cuidam e educam, mais a curiosidade das crianças se amplia e quanto mais sabem, mais querem saber. Transformar a curiosidade que pode ser passageira em necessidade de saber é o desafio que a educação infantil pode assumir para contribuir com o desenvolvimento da atividade de estudo no ensino fundamental. Para que essa necessidade se instale, é necessário que crianças vivam experiências que fortaleçam tais necessidades. A necessidade de aprender é o primeiro elemento desse processo que, no ensino fundamental tem a atividade de estudo como linguagem essencial de relação da criança com o mundo da cultura e da natureza que a rodeia.

De acordo com Leontiev (1978a), o conhecimento socialmente acumulado educa, no entanto, para isso é necessário educar nas novas gerações um sentido em relação ao conhecimento. Novos métodos de ensino devem se preocupar, portanto, não apenas com apresentar o conhecimento, mas fazê-lo de modo a criar nas crianças desde a educação infantil um sentido para o conhecimento (ZAPOROZHETS, 1987). A preocupação com a forma como propomos o encontro da criança com a cultura cresce também pelo fato de que no processo educativo não apenas possibilitamos às novas gerações a apropriação da experiência humana acumulada historicamente, mas também e essencialmente promovemos a formação e o desenvolvimento da personalidade e da inteligência de cada criança.

Se, em lugar de respondermos rapidamente e de forma simplificada às perguntas das crianças, as transformamos em pequenos projetos de investigação coletiva, as crianças vão aprendendo as fontes onde podem buscar conhecer o que lhes interessa e, também, a valorizar sua participação no processo de conhecer.

Da mesma forma, quando instigamos as crianças a solucionar problemas, quando Ihes damos tempo para pensar alternativas e discutir entre si, criamos nelas o prazer de resolver situações problemas. Por isso, iniciar a criança pequena na busca e exploração de diferentes fontes de informações - como livros, enciclopédias, dicionários, jornais, vídeos, revistas, entrevista a especialistas - sobre temas que chamam a atenção das crianças e sobre os quais elas querem saber mais é uma maneira de inserir as crianças pequenas na sistemática de conhecimento do mundo que envolve o estudo. Com isso, fortalecemos sua curiosidade sob a forma de vontade de saber mais, formando 
procedimentos ligados à atitude investigativa. Essa exploração pode combinar com atividades lúdicas como jogos de mesa, brincadeiras de papeis sociais, leitura de histórias, mas pode também culminar com a produção de um álbum ${ }^{8}$ sobre 0 tema que poderá ser distribuído para as famílias - o que contribui para a criação de novos motivos de conhecimento nas crianças desde pequenas.

Todos estes são desafios e superar as relações autoritárias que tiram a voz das crianças e ocupam sua vez, substituindo as relações em que o poder está nas mãos dos adultos por uma nova relação de poder compartilhado, será possivelmente o desafio mais radical e essencial de todos.

\section{Considerações Finais}

A entrada na escola de ensino fundamental é algo que marca a criança. Como afirma Leontiev (1988, p. 61), "é difícil exagerar a significação deste fato na vida infantil". Ao longo desse período que se aí se inicia, vai ocorrer a transição da brincadeira de papeis - como a linguagem por meio da qual a criança melhor se relaciona com o mundo, aprende e se desenvolve - para a atividade de estudo.

A atividade de estudo tem como fonte os conhecimentos científicos, o conteúdo que dará rumo ao desenvolvimento da criança em idade escolar, ao possibilitar a reprodução dos conhecimentos, habilidades e capacidades produzidas historicamente pela humanidade, alicerçando uma nova forma de pensamento: o pensamento teórico.

Para isso, a criança deverá ter vivido intensamente a infância pré-escolar formando funções psíquicas que servem de base para a atividade de estudo e 0 pensamento teórico: a percepção categorial, a memória e atenção voluntárias, a linguagem oral, o pensamento verbal, o autocontrole da conduta - e, com ela, a capacidade de guiar a conduta por regras -, a imaginação, a função simbólica da consciência, que se formam, todas elas, enquanto as crianças brincam de faz de conta assumindo papeis sociais.

CONTRA todas as formas de abreviamento da infância, Zaparozhetz (1987) afirma que a maneira de potencializar o desenvolvimento humano na infância NÃO é transformando a criança pequenininha em pré-escolar e o pré-escolar em escolar, mas

\footnotetext{
${ }^{8}$ Tal como faz, por exemplo, a Pedagogia Freinet.
} 
aprofundando as formas da atividade plástica - as múltiplas linguagens de expressão -, da atividade prática - a participação da criança na vida na escola - e a atividade lúdica a brincadeira de papeis sociais.

A abordagem histórico-cultural coloca para nós, professoras e professores, a possibilidade e a responsabilidade por promover a formação em cada criança das máximas possibilidades humanas. Resta a todos nós, pesquisadores e pesquisadoras, profissionais da educação infantil e do ensino fundamental ampliar o espaço de reflexão e a proposição de práticas que promovam a educação do pensamento das crianças.

Ao mesmo tempo, é fundamental nosso engajamento na criação e desenvolvimento de uma pedagogia que acolha, cuide e eduque as crianças de 0 a 10 anos: uma pedagogia que escute, investigue e reflita sobre os desafios colocados hoje para a educação de nossas crianças numa sociedade tão adversa ao desenvolvimento humano pleno e que protagonize a criação de uma nova cultura escolar em que sejamos todos - crianças, professores e professoras - protagonistas de uma educação que promova o máximo desenvolvimento humano sem abreviar ou apressar a infância.

\section{Referências}

DAVIDOV, Vasily Vasilovich. La enseñanza escolar y el desarrollo psíquico. Moscou: Editorial Progresso, 1988.

LEONTIEV, Alexis Nikolaevich. Uma contribuição à teoria do desenvolvimento da psique infantil. In: VIGOTSKII, Lev Semyonovich; LURIA, A.R.; LEONTIEV, Alexis Nikolaevich. Linguagem, desenvolvimento e aprendizagem. São Paulo: Ícone, 1988, p. 59-83.

LEONTIEV, Alexis Nikolaevich. Actividad, conciencia y personalidad. Buenos Aires: Ediciones Ciencias del Hombre, 1978a.

LEONTIEV, Alexis Nikolaevich. O homem e a cultura. In: LEONTIEV, Alexis Nikolaevich. 0 desenvolvimento do psiquismo. Lisboa: Livros Horizonte, 1978b. p.268-289.

FARIAS, Maria Auxiliadora S. de; MELLO, Suely Amaral. A escola como lugar da cultura mais elaborada. Educação, Santa Maria, v. 35, n. 1. p. 53-68, jan./abr. 2010.

GRAMSCI, Antonio. Os Intelectuais e a organização da cultura. Rio de J aneiro: Civilização Brasileira, 1979.

MARX, Karl. Manuscritos econômicos e filosóficos. São Paulo: Editora Martin Claret, 2006. 
PEDERIVA, P; ALMEIDA, S.; MELLO, Suely Amaral. Apresentação: Uma teoria para orientar nosso pensar e agir docentes na educação infantil. In: ALMEIDA, S.; MELLO, S. A. Teoria histórico-cultural na educação infantil: conversando com professoras e professores. Curitiba, Editora CRV, 2017. p. 5-13.

REINACH, Fernando. Neotenia e Educação Infantil. 0 Estado de São Paulo, p. A32, 25 de maio de 2013.

SÃO PAULO. Secretaria Municipal de Educação. Currículo Integrador da Infância Paulistana. 2015. Disponível em: http://portal.sme.prefeitura.sp.gov.br/Portals/1/Files/24900.pdf. Acesso em: 16 jul. 2016.

VIGOTSKI, Lev Semyonovich. Psicologia pedagógica. Porto Alegre: Artmed, 2003.

VIGOTSKI, Lev Semyonovich. Quarta aula: a questão do meio na pedologia. Psicologia USP, São Paulo, v. 21, n. 4, p. 681-701, 2010.

VIGOTSKII, Lev Semyonovich. Aprendizagem e desenvolvimento intelectual na idade escolar. In: VIGOTSKII, Lev Semyonovich.; LURIA, A.R.; LEONTIEV, Alexis Nikolaevich. Linguagem, desenvolvimento e aprendizagem. 2. ed. São Paulo: Ícone, 1988. p. 103-117.

VYGOTSKY, Lev Semyonovich. Obras escogidas. 2. ed. Madrid, España. Visor. 1995. v. 3.

VYGOTSKY, Lev Semyonovich. Obras escogidas. Madrid: Visor, 1996. v. 4.

ZAPORÓZHETS, A. Importância dos períodos iniciais da vida na formação da personalidade infantil. In: DAVIDOV, Vasily Vasilovich.; SHUARE, M. (org.). La psicologia evolutiva y pedagogica en la URSS (Antologia). Moscou: Editorial Progresso, 1987. p.345361. 